\section{CISTOCENTESIS SUPRAPUBICA}

\section{EN CIRUGIA VAGINAL}

\author{
(COMUNICACION PRELIMINAR)
}

Dr. Enrique Darnalt Restrepo*

Dr. Mario Riaño Rincón**

Dr. Elkin Lucena Quevedo***

Dr. Ricardo Ochoa Alcántara****

Las complicaciones más frecuentes de la cirugía ginecológica por vía vaginal son las afecciones del aparato urinario por lo cual el cuidado de la vejiga en el post-operatorio tiene gran importancia. Es tradicional el uso de la sonda de Foley en estas pacientes con el fin de lograr la descompresión permanente de la vejiga, durante 4 o 5 días. Cuando se mide el residuo, y es inferior a los $100 \mathrm{cc}$. se dá de alta a la paciente; en caso contrario, se deja la sonda por 24 horas o más, y en algunas ocasiones se requiere la práctica de cateterismos repetidos. Además, en las inter ${ }^{2}$ venciones mayores ginecológicas, en las cuales se trabaja cerca de la vejiga, o en los prolapsos uterinos de larga evolución, se corre el peligro de la atonía vesical post-operatoria bien por el procedimiento quirúrgico en sí o por la anestesia que disminuye el tono de la misma.

Se han ensayado múltiples variantes al procedimiento anterior, tales como el cierre intermitente de la sonda, aplicación local de diversas sustancias químicas, y en general los resultados han sido pobres. Igualmen- te se han usado antibióticos y antisépticos profilácticos, sin mayores resultados en lo que respecta a la infección urinaria desencadenada por la sonda. Otro problema es la retención vesical post-operatoria, causa frecuente de cistitis, y que expone a todo el aparato urinario a la infección si queda orina residual.

Kass (4) comprobó que al dejar una sonda en la vejiga durante 24 horas, con orinas estériles, la bacteriuria se presenta posteriormente en un 50\% de los casos y si se deja un drenaje continuo por más de 4 días la bacteriuria es del $98 \%$. Igualmente hemos visto que aún con las mejores medidas asépticas que se tomen en la colocación de la sonda el riesgo de la infección es muy alto.

Stamey y cols. (7) demostraron que el $2 \%$ de las mujeres en quienes

\footnotetext{
* Jefe del Servicio de Ginecología. Depto. Obst. y Gin. Hospital Militar Central.

** Especialista Asociado. Depto. Obst. Y Gin. Hospital Militar Central.

*** Residente III Depto. Obst. y Gin. Hospital Militar Central.

**** Residente III Depto. Obst. Y Gin. Hospital Militar Central.
} 
el cultivo de orina era negativo recolectando la muestra por aspiración suprapúbica, emitían una muestra contaminada por la uretra. Cox (2) señaló que excepcionalmente la uretra femenina es aséptica y que un solo cateterismo implica una contaminación para la vejiga. Practicó cultivos en 52 uretras femeninas con historia urológica normal y cultivos de orina negativos; mediante técnica especial encontró, que el primer centímetro de todas las uretras contenía bacterias lo cual incluía el meato y su parte más distal. Las dos porciones medias tenían bacterias en un porcentaje más bajo, pero significativo $(81 \%$ y $88 \%)$; el último centímetro contenía bacterias en el $54 \%$ de los casos y éstas se encontraban cerca del cuello vesical. Los gérmenes aislados fueron: en el 15,4\% bacilos difteroides y Staphylococcus no hemolíticos; el 26,9\% contenían Escherichia coli; Pseudomonas Bacilos paracoli o Aerobacter aerógenes. Organismos de patogenicidad dudosa, en el $57,6 \%$ de los cultivos, predominando en este grupo, Enterococcus, y Staphyloccccus albus.

Stern y Williams (8) han recomendado el cateterismo permanente durante 5 días para procedimientos plásticos vaginales y cirugía de la incontinencia urinaria de esfuerzo. En nuestra literatura, Rubén Darío Guzmán (3) llega a las mismas conclusiones y comenta además los problemas de la retención vesical después de retirada la sonda, que naturalmente aumentan la estancia hospitalaria.

\section{Objetivos}

Preocupados en nuestro Servicio por disminuir la infección urinaria, evitando la cateterización uretral después de la cirugía vaginal y la retención urinaria post-operatoria, con dis- minución del residuo vesical, proscribiendo los antibióticos y antisépticos profilácticos, y reduciendo la estancia hospitalaria ocasionada por complicaciones urinarias, utilizamos la "Microcistostomía Supra-púbica", de Taylor y Mickel con algunas modificaciones.

Revisamos el trabajo de Taylor y Mickel ( 8 ) basado en las inquietudes de Scorer (6) en Inglaterra, quien trató 150 hombres con obstrucción aguda del tracto urinario utilizando una sonda de Foley suprapúbica y colocándola, con escasas complicaciones, notó que la infección urinaria disminuía, pero observó a la cistoscopia gran cantidad de lesiones inflamatorias de pequeño diámetro. Por esta razón los autores citados cambiaron la sonda de Foley por un tubo de polietileno.

En la actualidad varios autores in vestigan la técnica de la Cistostomía Supra-púbica utilizando un catéter de polietileno. Entre ellos Cameron (1), Stamey y cols. (7) y Mathingly (5) en el Milwaukee Hospital. Taylor $y$ Nickel (L. C.) describen así la técnica: terminada la intervención, llenan la vejiga por medio de una sonda uretral con $200 \mathrm{cc}$. de una solución salina estéril, retirando enseguida la sonda; con una aguja hipodérmica No 13 (de 3 pulgadas de longitud), perforan la pared anterior de la vejiga a dos centímetros por encima del pubis; colocan luego a través de la aguja un tubo de polietileno de los usados para alimentar niños prematuros ( $N$ : 5), al cual le practican en uno de los extremos, 4 orificios, y retiran la aguja. El tubo de cistostomía actúa como u nsifón manteniendo la descompresión vesical, siendo el material plástico de éste menos irritante que la sonda de caucho.

Con estos procedimientos han obtenido, en 37 pacientes, tres días me- 
nos de drenaje y de hospitalización que en el grupo control manejado con la sonda de Foley en el cual, la bacteriuria, sin antibióticos, fue del $19 \%$.

Como complicaciones tuvieron: la punta de catéter pasó a la uretra en una paciente; otra presentó edema subcutáneo después de retirado el polietileno; una tercera, infección a nivel de la punción, y en algunas, prurito en el sitio de la misma.

\section{Método propuesto}

Utilizamos el sistema de Taylor y Nickel (9), simplificado por nosotros, en histerectomías vaginales, operación de Manchester, plastias vaginales, cirugía para incontinencia urinaria de esfuerzo por vía vaginal, etc., y la practicamos en 12 casos. Le hicimos algunas modificaciones que consideramos de interés:

1. Practicamos la Cistostomía previa a la intervención, para mantener la vejiga vacía, facilitando así la técnica operatoria.

2. No practicamos el cateterismo uretral y la inyección de soluciones estériles a través de la sonda, que Taylor y Nickel usan después de la cirugía para facilitar la punción, y evitamos así parte de las causas de infección vesical. En cambio, hacemos que la paciente no evacúe la vejiga nates de la cirugía, lográndose un buen globo vesical que facilita la Microcistostomía. Fundamentamos las modificaciones en los estudios de Cox ya mencionados.

Con estas variaciones se realiza una punción por encima del pubis con una aguja de Touhy № 13, dirigiéndola hacia abajo y atrás. Se pasa un tubo de polietileno № 160, de 20 cms. de longitud, perforado en un extremo con $3 \circ 4$ orificios para facilitar el drenaje. Este catéter se introduce a partir de la piel $13 \mathrm{cms}$. aproximadamente. Se retira la aguja y se empata el catéter a una aguja recortada $N$ ㅇ 18 a la cual se enchufa el equipo de drenaje.

\section{Manejo del Catéter}

El drenaje se deja 48 horas, lapso aproximado para que la paresia vesical y el edema ocasionados por la intervención hayan desaparecido y las pacientes tengan su primera micción voluntaria. Se dá un margen de 6 a 8 horas para que la micción se restaure; si no ocurre, hay retención y se restablecerá el drenaje por 24 horas más. Lograda la segunda micción voluntaria se mide el residuo vesical por aspiración a través del catéter con jeringa estéril y si éste es mayor de $100 \mathrm{cc}$. se continúa el drenaje. En caso contrario, se retira.

\section{Laboratorio}

A todas las pacientes se les ordenó un examen parcial de orina preoperatorio instruyéndolas sobre el modo de recolectarla; además, urocultivo, recuento de colonias y antibiograma de la orina tomada directamente del catéter de cistostomía en el momento de practicarla, lo que se repetirá antes de retirar el catéter. Anotamos que ninguna de nuestras pacientes, salvo casos especiales, recibió antibióticos o antisépticos.

Las 12 intervenciones practicadas que son materia de esta Comunicación preliminar se discriminan así:

Histerectomías vaginales con colpoperineorrafias . . . . . . 4

Colpoperineorrafias . . . . . . 6

Manchester . . 


\section{Deducciones}

Como sobre 12 casos no es posible presentar resultados de valor estadístico, en esta comunicación preliminar nos limitaremos a señalar los datos globales sin precisar porcentajes, así:

Primera micción post-operatoria: se presentó en promedio, a las 50 horas.

Segunda micción post-operatoria: se presentó a las 52 horas. Residuo vesical después de la segunda micción: arrojó como promedio la cantidad de $13 \mathrm{cc}$.

Tiempo de permanencia del catéter: promedio total: 53 horas.

En relación a la infección urinaria estudiada por medio de los urocultivos, obtuvimos:

8 de los casos comenzaron con urocultivo negativo y finalizaron en igual forma.

2 de los casos fueron negativos inicialmente, pero tuvieron un recuento de más de 100.000 colonias al final, porque las muestras fueron enviadas tardíamente al laboratorio y se contaminaron.

1 caso tuvo más de 100.000 colonias en el primer control y el segundo urocultivo fué negativo.

1 caso presentó 100.000 colonias iniciales y terminó con el mismo recuento.

En resumen: en 10 de los casos no se presentó ni se incrementó la cantidad de colonias. Además, no hubo retención urinaria ni complicaciones en el sitio de la cistostomía.

Mientras tenemos un número suficiente de caso scon valor estadístico, presentamos las impresiones de esta etapa preliminar.
1. La micción se restableció precozmente.

2. El residuo vesical disminuyó en forma notable.

3. Se eminoró el tiempo de drenaje vesical de 96 a 120 horas con sonda de Foley, a 53 horas.

4. Bajó la incidencia de infección urinaria en forma notoria.

5. No hubo retención vesical después de retirado el catéter.

6. Las molestias urinarias subjetivas, tales como: disuria, polaquiuria y "urgencia'í se reducen al mínimo.

7. La estancia hospitalaria se redujo por la disminución de complicaciones de tipo urinario.

8. Las complicaciones citadas por Taylor y Nickel no se observaron.

9. La Microcistostomía incomoda menos que la sonda de Foley.

10. Esta forma de cuidado postoperatoria de la vejiga puede ser muy útil si el estudio estadístico comprueba su valor.

\section{BIBLIOGRAFIA}

1 CAMERON, E.: Urinary retention managed Withouth urethral catheterization. Lancet. 2: 606, 1963.

2 COX, CLAIR E.: La uretra y su relación con infecciones del tracto urinario; flora normal de la uretra femenina normal. Year Book of Urology. 1: 14, 1966-67.

3 GUZMAN, RUBEN DARIO: Manejo de la sonda vesical en el post-operatorio de Cirugía Vaginal. Revista Col. Obst. y Gin. 6: 333, 1964.

4 KASS, E. H.: Entry of bacteria into the urinary tract of patients with including catheters. New Engl. J. Med. 256: 556, 1957.

5 MATTINGLY, R. F.: Comunicación personal. Citado por Stern, B. L. and Williams, T. J. (8). 
6 SCORER, C. G.: The suprapubic catheter. Lancet. 6798: 1222, 1953.

7 STAMEY, T. A., GOVAN, D. E. Y PALMER, J. M.: Localización and treatment of urinary tract infections: The role of bactericidal urine levels as opposed to serum levels. Medicine. 44: 1, 1965. Citado por Stern, B. L. and Williams, T. J. (8).
8 STERN, B. L. and WILLIAMS, T. J.: Asistencia de la vejiga después de cirugía ginecológica. Clínicas obst. y Gin. 1: 192, 1967.

9 TAYLOR, B. D. and NICKEL, J. E.: Suprapubic Cystostomy and the use of polyethylene tubing. Obst. and Gynec. 6: 854, 1966. 